\title{
Novel and Efficient Method for the Synthesis of 4-Chloro-5, 6-dihydro Pyran Derivatives using Lewis Acidic Chloroaluminate Ionic Liquids
}

\author{
N. MARUTHI RAJU ${ }^{2,3}, \mathrm{~K}$. RAJASEKHAR ${ }^{1 *}$, \\ J. MOSES BABU ${ }^{2}$ and B. VENKATESWARA RAO ${ }^{3}$ \\ ${ }^{1}$ Ragas Pharmaceuticals Private Limited (OPC), IDA Cherlapally, Hyderabad, 500051, India. \\ ${ }^{2}$ Custom Pharmaceutical Services, Dr Reddy's Laboratories Limited, \\ Bollaram Road, Miyapur, Hyderabad, 500049, India. \\ ${ }^{3}$ Department of Organic Chemistry, Foods, Drugs and Water, \\ Andhra University, Visakhapatnam, 530003, India. \\ ${ }^{*}$ Corresponding author E-mail: koorella.rajasekhar@gmail.com \\ http://dx.doi.org/10.13005/ojc/320459
}

(Received: May 30, 2016; Accepted: August 07, 2016)

\begin{abstract}
The reaction of aldehydes/ketones with homopropargylic alcohols in the presence of 1-nButyl-3-methylimidazolium chloroaluminate $[\mathrm{bmim}] \mathrm{Cl} \cdot \mathrm{AlCl}_{3}(\mathrm{~N}=0.56-0.67)$ ionic liquid generates the 4-chloro-5,6-dihydro-2H-pyran derivatives in excellent yield and in short reaction times.
\end{abstract}

Keywords: 1-n-Butyl-3-methylimidazolium chloroaluminate, Aldehydes, Ketones, Homopropargylic alcohols, 4-chloro-5,6-dihydro-2H-pyran derivatives.

\section{INTRODUCTION}

Substituted dihydropyrans are the key intermediates for the synthesis of many natural products ${ }^{1}$.Many natural products like Swinholides ${ }^{2 a}$, Laulimalides $^{2 b}$, Ambruticins ${ }^{2 c}$ and Jerangolids ${ }^{2 \mathrm{~d}}$ contains dihydropyran skeleton. Moreover, the olefin function is having synthetic value for further functionalization in obtaining polysubstituted tetrahydropyrans ${ }^{3}$. The coupling of alkynes to aldehydes is an important transformation in organic synthesis ${ }^{4}$. The direct synthesis of dihydropyrans by the coupling of alkynes to aldehydes provides a useful synthetic method for the synthesis of dihydropyrans. Although other methods were reported ${ }^{5}$, Consequent methods that successfully minimize the use of toxic and volatile organic solvents are the focus of much attention. In this respect, ionic liquids are attracting growing interest as alternative reaction media for various chemical and biotransformations ${ }^{6}$. In particular, choloroaluminate ionic liquids are having Lewis acidity, which can be varied over a wide range, and their intrinsic ability to solvate a variety of substances. These ionic liquids are easily prepared from $\mathrm{AlCl}_{3}$ and 1-butyl-3-methylimidazolium chloride. These chloroaluminate ionic liquids have 
the advantage of being liquid at room temperature over a considerable composition range of apparent mol fraction of $\mathrm{AlCl}_{3}(N=0.30-0.67)$ and also have negligible vapour pressures, making them useful alternatives to conventional molecular organic solvents for various synthetically useful transformations ${ }^{7}$. Furthermore, chloroaluminate ionic liquids play dual roles both as Lewis acid catalyst and as solvent.

\section{RESULTS AND DISCUSSION}

In view of the emerging importance of the use of lonic liquids as cost-effective and environmentally benign catalysts, we herein describe a simple and efficient protocol for the cyclization reactions of aldehydes and homopropargylic alcohols to produce dihydropyrans using 1-n-Butyl-3-methylimidazolium chloroaluminate $[\mathrm{bmim}] \mathrm{Cl} \cdot \mathrm{AlCl}_{3}(\mathrm{~N}=0.56-0.67)$ ionic liquid under mild reaction conditions (Scheme I).<smiles></smiles>

\section{Scheme I}

For instance treatment of benzaldehyde with 3-butyn-1-ol in [bmim] $\mathrm{Cl} \cdot \mathrm{AlCl}_{3}$ ionic liquid afforded dihydropyran in $70 \%$ yield. The reaction is very clean and complete within $30 \mathrm{sec}$. at room temperature. In a similar manner, various aldehydes and ketones underwent smooth cyclization reaction with homopropargylic alcohols to give the corresponding dihydropyran derivatives in high yields. In all cases, the reactions proceeded readily at room temperature with high efficiency. The reaction worked well both with aromatic, aliphatic aldehydes and ketones. When symmetrical ketones like cyclohexanone and 3-pentanone reacted with $\mathbf{2 c}$ and $\mathbf{2} \mathbf{d}$ the formation of single product was observed. But when applied to aldehydes the formation of a mixture of the isomers were observed by TLC and ${ }^{1} \mathrm{HNMR}$ spectrum. This is due to the formation of the diastereomers in the later case (Scheme II).



1<smiles>[R]C(O)CC#C</smiles>

2

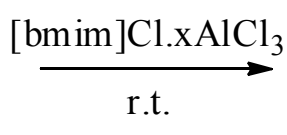

\section{Scheme II}

The mechanism for the formation of dihydropyrans can be explained by the attack of homopropargylic alcohol and cyclised to the dihydropyran carbenium ion which is further attacked by the chloride nucleophile to form the 4-Chloro dihydropran derivative (Scheme III).

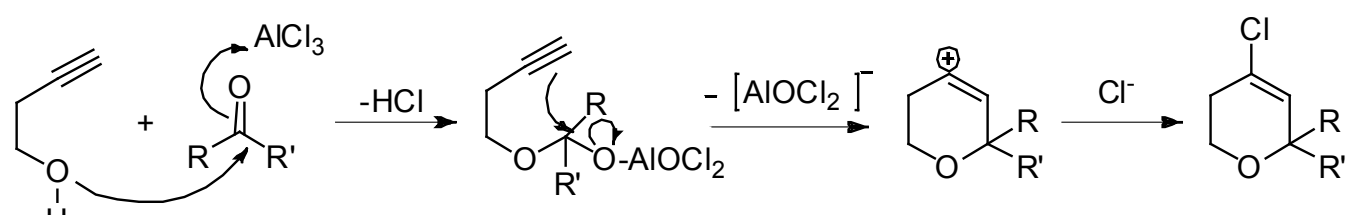

\section{Scheme III}


Table I - Lewis Acidic Chloroaluminate Ionic Liquid promoted synthesis of 4-chloro-5,6-dihydro pyran derivatives

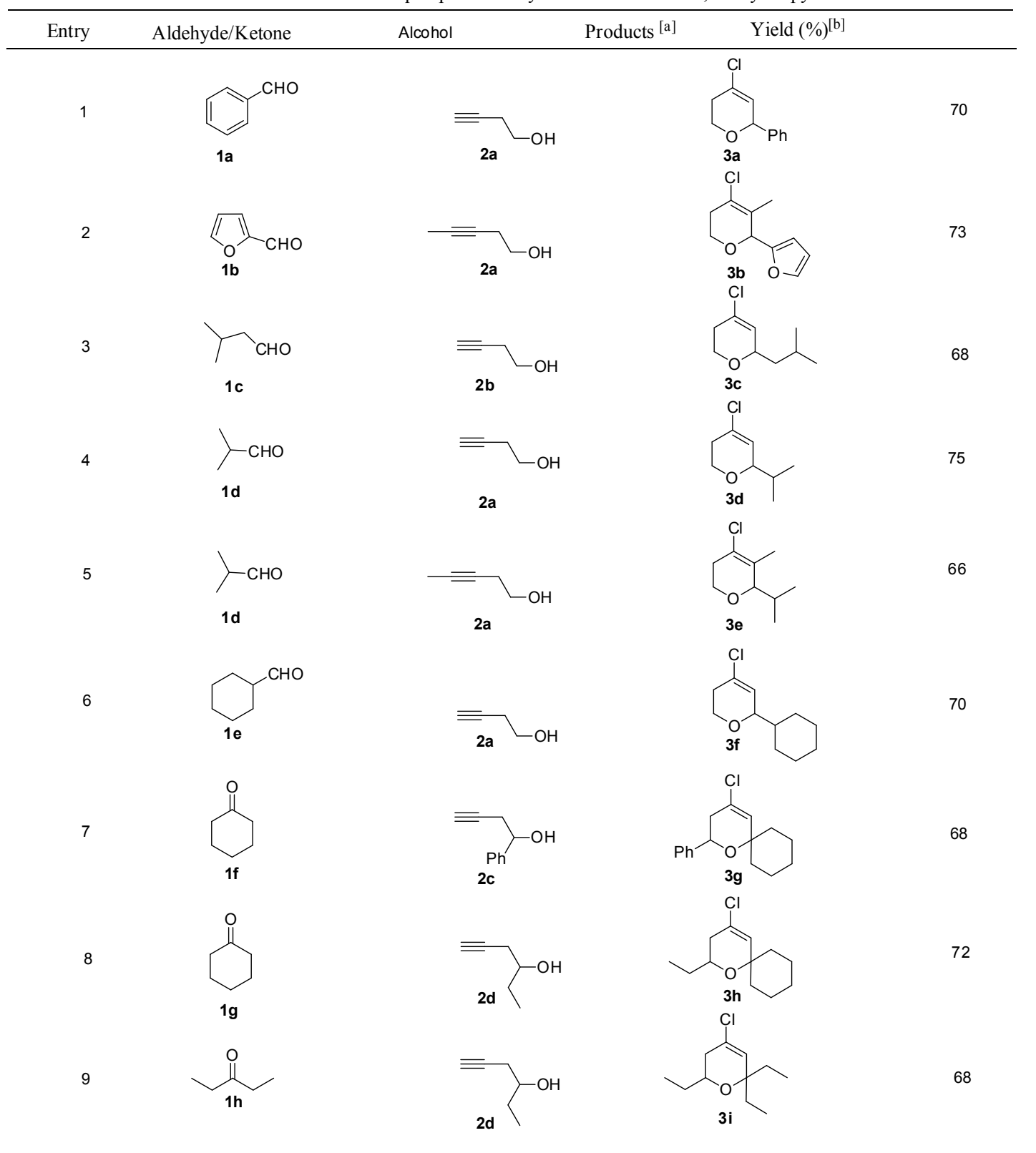

${ }^{\mathrm{a}} \mathrm{All}$ the products were characterized by ${ }^{1} \mathrm{H}$ NMR and mass spectroscopy and compared with previously reported data.

${ }^{b}$ Yields are isolated after column chromatography.

\section{CONCLUSION}

In summary, we have described a green protocol for the preparation of dihydropyran derivatives through cyclization reaction of aldehydes/ ketones with homopropargylic alcohols using 1-n-
Butyl-3-methylimidazolium chloroaluminate ionic liquid system. The attractive features of this process are the mild reaction conditions, eco-friendly reagent, short reaction times and cleaner reactions with good yields, which makes it a useful process for the synthesis of dihydropyran core structure. 


\section{Experimental Section}

Chloro Aluminate Ionic liquids were prepared as described previously ${ }^{8}$.

\section{General Procedure}

To a mixture of benzaldehyde (500 $\mathrm{mg}, 4.71 \mathrm{mmol}$ ) and 3-butyn-1-ol (330 mg, 4.71 $\mathrm{mmol}$ ) was added 1-n-Butyl-3-methylimidazolium chloroaluminate $(2 \mathrm{~mL})$ at room temperature. The mixture was stirred for $30 \mathrm{sec}$. and the reaction mass was quenched with icecold water and extracted with diethyl ether (10-15 mL). The combined organic layers were dried over anhydrous $\mathrm{Na}_{2} \mathrm{SO}_{4}$, concentrated in vacuo and purified by column chromatography on silica gel (Merck, 60-120 mesh, ethyl acetate/hexane, 2.0-8.0) to afford dihydropyran 3a. The products were characterized by IR, NMR and mass spectroscopy. All the products $\mathbf{3 b}$-i were prepared by the same procedure.

\section{ACKNOWLEDGEMENTS}

NMR thanks Dr Reddy's Laboratories for permitting the research work.

\section{REFERENCES}

(a) Oishi T., Ohtsuka Y., Studies in Natural Products Synthesis, edited by Atta-urRahman, (Elsevier, Amsterdam), 3, 1989, 73; (b) Yet L, Chem Rev, 100, 2000, 2963.

(a) Hayakawa H \& Miyashita M, Tetrahedron Lett, 41, 2000, 707; (b) Mulzer J \& Hanbauer M, Tetrahedron Lett, 2000, 41, 33; Connor D T, Greenough R C \& Strandtmann M, J. Org. Chem, 42, 1977, 3664; (d) Gerth K, Washausen P, Hoftle G, Irschik H \& Reichenbach H, J Antibiot, 49, 1996, 71. (a) Boivin T L B, Tetrahedron, 43, 1987, 3309; (b) Coppi L, Ricci A \& Taddei M J Org Chem, 53, 1988, 913 (c) Li C J \& Zhang W C, Tetrahedron, 56, 2000, 2403 (d) Schmidt B \& Westhus M, Tetrahedron, 56, 2000, 2421. Tetrahedron Lett, 46, 2005, 1311; (b) Frantz D E, Fassler R, Carreira E M, J Am Chem Soc,

122, 2000, 1806; (c) Anand N K, Carreira E M, J Am Chem Soc, 123, 2001, 9687; (d) Tzalis D \& Knochel P, Angew Chem, 38, 1999, 1463 (e) Miranda P O, Diaz D D, Padron J I, Bermejo J \& Martin V S, Org Lett, 5, 2003, 1979.

$5 \quad$ Miranda P O, Diaz D D, Padron J I, Bermejo J \& Martin V S, Org Lett, 5, 2003, 1979

6 (a) Sheldon R, Chem Commun 2001, 2399;

(b) Welton T Chem Rev, 99, 1999, 2071; (c) Wasserscheid P \& Keim W, Angew Chem Int Ed, 39, 2000, 3772.

(a) Namboodari V V \& Verma R S Chem Commun 2002, 342; (b) Potdar M K, Mohlile S S \& Salunkhe M M, Tetrahedron Lett, 42, 2001, 9285; (c) Ren R X \& Wu J X, Org Lett 3, 2001, 3727.

8 Wilkes J S, Levisky J A, Wilson R A \& Hussey C L, Inorg Chem, 21, 1982, 1263. 